\title{
RESEARCH
}

\section{Home safety measures and the risk of unintentional injury among young children: a multicentre case-control study}

\author{
John C. LeBlanc, I. Barry Pless, W. James King, Harry Bawden, Anne-Claude Bernard-Bonnin, \\ Terry Klassen, Milton Tenenbein
}

Published at www.cmaj.ca on Sept. 2I, 2006.

$\infty \quad$ See related articles, pages 867 and 899

\section{ABSTRACT}

Background: Young children may sustain injuries when exposed to certain hazards in the home. To better understand the relation between several childproofing strategies and the risk of injuries to children in the home, we undertook a multicentre case-control study in which we compared hazards in the homes of children with and without injuries.

Methods: We conducted this case-control study using records from 5 pediatric hospital emergency departments for the 2 -year period $1995^{-1996}$. The 351 case subjects were children aged 7 years and less who presented with injuries from falls, burns or scalds, ingestions or choking. The matched control subjects were children who presented during the same period with acute non-injury-related conditions. A home visitor, blinded to case-control status, assessed 19 injury hazards at the children's homes.

Results: Hazards found in the homes included baby walkers ( $21 \%$ of homes with infants), no functioning smoke alarm ( $17 \%$ of homes) and no fire extinguisher ( $51 \%$ of homes). Cases did not differ from controls in the mean proportion of home hazards. After controlling for siblings, maternal education and employment, we found that cases differed from controls for 5 hazards: the presence of a baby walker (odds ratio $[O R]$ 9.0, 95\% confidence interval $[\mathrm{CI}]$ 1.1-71.0), the presence of choking hazards within a child's reach (OR 2.0, $95 \% \mathrm{Cl}$ 1.0-3.7), no child-resistant lids in bathroom (OR 1.6, $95 \% \mathrm{Cl}$ 1.0-2.5), no smoke alarm (OR 3.2, 95\% Cl 1.4-7.7) and no functioning smoke alarm (OR 1.7, 95\% Cl 1.0-2.8).

Interpretation: Homes of children with injuries differed from those of children without injuries in the proportions of specific hazards for falls, choking, poisoning and burns, with a striking difference noted for the presence of a baby walker. In addition to counselling parents about specific hazards, clinicians should consider that the presence of some hazards may indicate an increased risk for home injuries beyond those directly related to the hazard found. Families with any home hazard may be candidates for interventions to childproof against other types of home hazards.

CMAJ 2006;175(8):883-7
I njuries cause almost half of all deaths among children aged I-4 years. ${ }^{1}$ Most home injuries involving children under 5 years old are caused by falls from heights, burns and scalds, and poisonings ${ }^{2}$ and are presumed to be preventable through removal of particular hazards. Interventions designed to reduce home injuries have focused on removal of a particular hazard (e.g., reduction in hot water temperature) or on intensive broad educational strategies (e.g., "childproofing" a house). However, few studies have examined the relation between the presence of hazards and the risk of injuries upon which these interventions depend. Only a minority of randomized controlled trials (RCTs) conducted to date have supported the relation between reduction in home hazards and reduction in injuries. A systematic review of interventions to increase smoke detector use identified only 2 of 29 studies in which both smoke detector use and burn-related injuries were measured. ${ }^{3}$ One RCT of health education interventions to childproof homes measured the number of injury hazards and injury rates but failed to show an impact on either measure. ${ }^{4}$ Another trial of a childproofing education intervention did show statistically significant reductions in injury hazards, but it failed to show a reduction in injury rates, in part because of the study's insufficient power for the latter outcome. ${ }^{5}$ A systematic review of 22 interventions designed to reduce home injuries called for more observational studies to better understand the relation between hazards and injuries. This would facilitate the design of more effective future interventions. ${ }^{\circ}$

A few observational studies have provided evidence for a direct relation between specific hazards and specific injuries. In one study, the introduction of child-resistant containers was associated with a reduction in the number of deaths caused by ingestion of prescription drugs. ${ }^{7}$ An economic analysis presented evidence that $75 \%$ of childhood firerelated deaths could be prevented in homes with working smoke alarms, sprinkler systems, anti-scald devices, slowburning cigarettes and childproof lighters. ${ }^{8}$ Finally, findings of 3 observational studies provided evidence for an association between smoke detector use and reduced fire-related

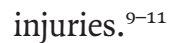

To better understand the relation between several childproofing strategies and the risk of injuries to children in the 
home, we undertook a multicentre case-control study in which home visitors measured the presence of hazards for home injury. We wished to determine whether the households of children who sustained a home injury had a higher proportion of injury hazards than the households of children who had not sustained a home injury. A secondary objective was to assess whether homes of cases and controls differed with respect to individual hazards.

\section{Methods}

Participants were identified from 1995 to 1996 by daily screening of the emergency department logs of 5 Canadian children's hospitals: the IWK Health Centre in Halifax, the Montreal Children's Hospital and Hôpital Sainte-Justine in Montréal, the Children's Hospital of Eastern Ontario in Ottawa and the Winnipeg Children's Hospital. Cases were defined as children younger than 8 years who presented because of a fall, scald, burn, poisoning, ingestion or choking episode at home. Controls were matched to each case by sex and age (within 6 months) and consisted of children who presented to the same emergency department with a non-injury-related diagnosis (e.g., diarrhea or otitis media).

Almost all home visits were made within I month after the initial emergency department visit. Following a defined protocol and blinded to the subjects' case-control status, a home visitor collected demographic data and inspected the home for hazards associated with injuries to children. Hazards for falls were the presence of a baby walker, no device to prevent child opening basement door, no gates at stairs, no

Table 1: Characteristics of children who presented with home injuries (cases) and children who presented with acute non-injury-related conditions (controls) to pediatric emergency departments

\begin{tabular}{|c|c|c|c|c|}
\hline \multirow{3}{*}{$\begin{array}{l}\text { Characteristic } \\
\text { Sex, female }\end{array}$} & \multicolumn{3}{|c|}{ No. (\%) of children* } & \multirow{3}{*}{$\frac{p \text { value }^{\dagger}}{0.85}$} \\
\hline & \multicolumn{2}{|c|}{$\begin{array}{c}\text { Cases } \\
n=346\end{array}$} & \multirow{2}{*}{$\begin{array}{c}\begin{array}{c}\text { Controls } \\
n=346\end{array} \\
138 / 346 \quad(39.9)\end{array}$} & \\
\hline & $143 / 346$ & $(41.3)$ & & \\
\hline \multicolumn{5}{|l|}{ Age, yr } \\
\hline$\leq 1$ & $160 / 322$ & $(49.7)$ & $158 / 329(48.0)$ & \\
\hline$>1$ and $\leq 3$ & $106 / 322$ & $(32.9)$ & $116 / 322(36.0)$ & \\
\hline$>3$ and $<8$ & $56 / 322$ & $(17.4)$ & $55 / 322(17.1)$ & 0.70 \\
\hline$\geq 1$ sibling & $220 / 346$ & $(63.6)$ & $192 / 346(55.5)$ & 0.03 \\
\hline \multicolumn{5}{|l|}{ Mother's age, yr } \\
\hline$<25 \mathrm{yr}$ & $35 / 346$ & $(10.1)$ & $46 / 344(13.4)$ & \\
\hline$\geq 25$ and $<35 \mathrm{yr}$ & $222 / 346$ & $(64.2)$ & $213 / 344$ (61.9) & \\
\hline$\geq 35 \mathrm{yr}$ & $88 / 346$ & $(25.4)$ & $85 / 344$ (24.7) & 0.48 \\
\hline Mother's education $<12 \mathrm{yr}$ & $44 / 332$ & $(13.2)$ & $60 / 334(18.0)$ & 0.09 \\
\hline $\begin{array}{l}\text { Either parent in labour or } \\
\text { service sector }\end{array}$ & $129 / 346$ & $(37.3)$ & $151 / 346(43.6)$ & 0.09 \\
\hline $\begin{array}{l}\text { Father unemployed or } \\
\text { house-parent }\end{array}$ & $16 / 346$ & $(4.6)$ & $14 / 346 \quad(4.0)$ & 0.71 \\
\hline
\end{tabular}

*Denominators differ because of missing data.

†Difference between cases and controls by conditional logistic regression analysis. safety straps on diaper change table, bedroom windows that open easily and beyond $15 \mathrm{~cm}$ and living room windows that open easily and beyond $15 \mathrm{~cm}$. Hazards for poisonings or ingestions were choking hazards within child's reach in bedroom or in living room, no child-resistant lids on bathroom bottles, no child-resistant lids on household cleaning supplies, easy access to bathroom beauty supplies or medications and easy access to household cleaning supplies. Hazards for burns or scalds were tap water temperature greater than $54^{\circ} \mathrm{C}$ in kitchen, cords dangling from kettle or appliances in kitchen, no stove guard to prevent child from grabbing pots, no smoke detector, no functioning smoke detector, no fire extinguisher and matches or lighters within child's reach. The proportion of injury hazards was calculated by dividing the actual number of hazards found in the home by the total number of potential hazards. Certain hazards were excluded when considered not relevant. Baby walkers were analyzed only for households with an infant less than I year of age. In households with no children under 3 , the following hazards were ignored: no device to prevent child from opening basement door, no gates at stairs, no safety straps on diaper change tables and no objects within child's reach.

We assessed the difference in proportions of home hazards between cases and matched controls by using paired $t$ tests. We assessed the relation between specific hazards and the odds of being a case or control by using univariable and multivariable conditional logistic regression analysis. We controlled for potential confounders, defined as variables that differed between cases and controls at $p<0$.I, using a backward stepwise model. The least significant contributors to model fit were removed in sequence until the removal was insignificant according to the likelihood ratio test at a level of $p<0.05$.

Assuming $80 \%$ power and a $5 \% 2-$ sided type I error rate, we derived a sample size of 342 case-control pairs to detect an odds ratio of $\mathrm{I} .5$ for a baseline hazard proportion of $80 \%$ and an odds ratio of $\mathrm{I} .36$ for a baseline proportion of $50 \% .{ }^{12}$ The study was approved by the Research Ethics Board of the Montreal Children's Hospital.

\section{Results}

We obtained data for 346 matched case-control pairs and eliminated io unmatched subjects. The characteristics of the case subjects were similar to those of the control subjects except for the proportion with I or more siblings $(63.6 \%$ v. $55.5 \%$ respectively) (Table I). The distribution of injuries was as follows: falls $(50.4 \%)$, burns $(22.8 \%)$, poisonings (I6.0\%) and chokings (I0.8\%). Of the I77 falls, I04 (58.8\%) involved stairs, 7 
(4.0\%) involved baby walkers, I4 (7.9\%) were from changing tables, and I (o.6\%) was through an open window; the cause was not specified for $5 \mathrm{I}(28.8 \%)$. Of the 80 burn injuries, 8 were due to exposure to hot tap water (I0.0\%), 27 to hot liquids or solids $(33.7 \%), 22$ to hot surfaces $(27.5 \%)$ and 2 to dwelling fires $(2.5 \%)$; the cause was not specified for $2 \mathrm{I}(26.3 \%)$. Of the 56 poisonings, 25 (44.6\%) were due to medications and ro to household chemicals (17.9\%); for 2I $(37.5 \%)$ the cause was not specified. Of the 38 choking episodes, II (28.9\%) involved coins and 27 (7I.I\%) had no cause specified. Baby walkers were present in $32.3 \%$ of the case homes with at least I child less than I year old, as compared with $9.4 \%$ of the control homes $(p=0.003)$. Families with I or more children under 3 years of age lacked safety locks to prevent basement doors being opened in $50 \%$ of homes and lacked safety gates at stairs in $40 \%$ of homes. There were no smoke detectors in $6 \%$ of the homes and, where detectors were present, $17 \%$ were not functional. As well, $54 \%$ of the homes lacked fire extinguishers. The temperature of kitchen tap water was greater than $54^{\circ} \mathrm{C}$ in $43 \%$ of the homes.

The mean number of injury hazards was 7.0 in the homes of the cases, compared with 6.6 in the homes of the controls $(p=0.018)$. The proportion of injury hazards, after accounting for the age of children, was 0.39 in the case homes and 0.37 in the control homes $(p=0.09)$. The hazards for which there was a significant difference in crude odds ratios between the cases and controls were choking hazards within child's reach in bedroom, no child-resistant lids on bathroom bottles and no smoke detector (Table 2). The presence of a baby walker and no functioning smoke detector did not reach statistical significance. The adjusted odds ratios for these 5 factors had roughly the same magnitude as the crude odds ratios, but the presence of a baby walker and no functioning smoke detectors were now significant factors (Table 3 ).

\section{Interpretation}

There was little difference in the overall proportion of home hazards between the cases and their matched controls. Therefore, our primary hypothesis - that the proportion of potential hazards would be higher in the homes of cases than in the homes of controls - was not supported. After controlling for potential confounders, we found that the homes of cases did differ significantly from the homes of

Table 2: Proportion of homes with injury hazards to which cases and controls were exposed

\begin{tabular}{|c|c|c|c|c|}
\hline Hazard & $\begin{array}{l}\text { No. of case-control } \\
\text { pairs* }\end{array}$ & $\begin{array}{l}\text { No. of } \\
\text { cases }\end{array}$ & $\begin{array}{l}\text { No. of } \\
\text { controls }\end{array}$ & OR $(95 \% \mathrm{Cl})$ \\
\hline \multicolumn{5}{|l|}{ Related to falls } \\
\hline Presence of a baby walkert & 31 & 10 & 3 & $4.50(0.97-20.83)$ \\
\hline No device to prevent child opening basement doorł & 93 & 40 & 53 & $0.61(0.35-1.08)$ \\
\hline No gates at stairs $¥$ & 84 & 46 & 55 & $0.62(0.33-1.19)$ \\
\hline No safety straps on diaper change table $\neq$ & 48 & 22 & 18 & $1.44(0.62-3.38)$ \\
\hline Bedroom windows open easily and beyond $15 \mathrm{~cm}$ & 339 & 203 & 201 & $1.03(0.75-1.40)$ \\
\hline Living room windows open easily and beyond $15 \mathrm{~cm}$ & 339 & 173 & 175 & $0.98(0.72-1.32)$ \\
\hline \multicolumn{5}{|l|}{ Related to poisoning or ingestion } \\
\hline In bedroom, choking hazards within child’s reachł & 233 & 35 & 18 & $2.50(1.28-4.88)$ \\
\hline In living room, choking hazards within child's reachł & 243 & 44 & 34 & $1.31(0.81-2.12)$ \\
\hline No child-resistant lids on bathroom bottles & 308 & 106 & 74 & $1.70(1.18-2.44)$ \\
\hline No child-resistant lids on household cleaning supplies & 284 & 154 & 153 & $1.02(0.70-1.48)$ \\
\hline Easy access to bathroom beauty supplies or medications & 336 & 129 & 125 & $1.06(0.76-1.47)$ \\
\hline Easy access to household cleaning supplies & 337 & 141 & 137 & $1.05(0.77-1.45)$ \\
\hline \multicolumn{5}{|l|}{ Related to burns or scalds } \\
\hline In kitchen, tap water temperature higher than $54^{\circ} \mathrm{C}$ & 338 & 140 & 154 & $0.85(0.62-1.15)$ \\
\hline In kitchen, kettle or appliances with dangling cords & 251 & 9 & 14 & $0.64(0.28-1.49)$ \\
\hline No stove guard to prevent child from grabbing pots & 345 & 340 & 339 & $1.20(0.37-3.93)$ \\
\hline No smoke detector & 343 & 29 & 12 & $2.89(1.35-6.16)$ \\
\hline No functioning smoke detector & 314 & 61 & 43 & $1.54(0.99-2.39)$ \\
\hline No fire extinguisher & 340 & 185 & 183 & $1.02(0.75-1.40)$ \\
\hline Matches or lighters within child's reach & 344 & 48 & 39 & $1.30(0.81-2.09)$ \\
\hline
\end{tabular}

Note: $\mathrm{OR}=$ odds ratio, $\mathrm{Cl}=$ confidence interval

*Numbers differ because certain hazards were excluded when not considered relevant in the household.

†Restricted to households that had a child $<1$ years old.

$\ddagger$ Restricted to households that had a child $<3$ years old. 
controls with respect to 5 specific hazards across the injury domains of falls, burns, poisonings and ingestions. Homes of both cases and controls had concerning rates of hazards: $17 \%$ of the households lacked functioning smoke detectors, and $2 \mathrm{r} \%$ of homes with children less than I year old had baby walkers. Cases and controls differed the most with respect to baby walker use (adjusted odds ratio 9, albeit with a wide confidence interval). This difference could not be explained by level of maternal education or type of parental occupation. Baby walkers were banned in Canada in 2004; however, in response to a request from industry, the Minister of Health established a board to review this ban in June 2006. ${ }^{13}$ Most homes had windows accessible to toddlers that could be opened beyond $15 \mathrm{~cm}$, access to household supplies without child-resistant caps, no fire extinguisher and, in $98 \%$ of homes, no stovetop guards.

Our primary hypothesis implied that parents would, on average, be attentive to safety to the same extent regardless of the type of injury (e.g., parents who had safe practices with respect to falls were likely to have safe practices with respect to ingestions). If this were the case, a home hazard score or proportion (with implicit equal weights for all hazards) would be a reasonable way to quantify this, as used in 3 RCTs, ${ }^{5,14,15}$ I cross-sectional survey ${ }^{16}$ and I cohort study. ${ }^{17}$ In the 2-year cohort study involving 2357 children aged 7 years or less, fitted and working smoke detectors, safe storage of sharp objects and use of stair gates predicted decreased hospital admissions for all injuries, but only smoke detectors predicted decreased emergency department visits. ${ }^{17}$ This confirms our finding that individual hazards are associated with an increase in overall home injuries that cannot be explained by the individual mechanisms of injury

Table 3: Relation between specific hazards and odds of home injury*

\begin{tabular}{|c|c|c|}
\hline Hazard & $\begin{array}{c}\text { No. of } \\
\text { case-control pairs }\end{array}$ & OR $(95 \% \mathrm{Cl})$ \\
\hline Presence of a baby walker & 29 & $9.00(1.14-71.04)$ \\
\hline $\begin{array}{l}\text { In bedroom, choking hazards within } \\
\text { child's reach }\end{array}$ & 224 & $1.95(1.03-3.70)$ \\
\hline$\geq 1$ sibling & & $1.84(1.23-2.77)$ \\
\hline Mother has $<12 \mathrm{yr}$ education & & $0.56(0.33-0.97)$ \\
\hline $\begin{array}{l}\text { No child-resistant lids on bathroom } \\
\text { bottles }\end{array}$ & 206 & $1.63(1.05-2.53)$ \\
\hline$\geq 1$ sibling & & $1.89(1.24-2.87)$ \\
\hline Mother has $<12$ yr education & & $0.55(0.31-0.97)$ \\
\hline No smoke detector & 318 & $3.25(1.37-7.71)$ \\
\hline$\geq 1$ sibling & & $1.50(1.08-2.09)$ \\
\hline Parent in service or labour sector & & $0.68(0.49-0.96)$ \\
\hline No functioning smoke detector & 293 & $1.69(1.03-2.76)$ \\
\hline$\geq 1$ siblings & & $1.52(1.08-2.13)$ \\
\hline Parent in service or labour sector & & $0.67(0.47-0.96)$ \\
\hline
\end{tabular}

Note: $\mathrm{OR}=$ odds ratio, $\mathrm{Cl}$ = confidence interval.

"Backwards stepwise logistic regression model in which the following potential confounders were

controlled for: presence of siblings in the home, level of mother's education and parent participation in labour or service sector. associated with a hazard. This suggests that these associations are not a result of chance. The lack of a functional smoke detector was the sole factor associated with injuries in both this cohort ${ }^{17}$ and in our study. Although this could be a chance association, it may reflect a higher level of home injury prevention among parents who are conscious of fire safety.

A particular strength of our study is the collection of data through observation during a home visit rather than reliance on a written or verbal report. Because I or more weeks elapsed since the emergency department visit, caregivers could have eliminated common hazards. However, they did not know the specific content of the survey and could not have removed most items, except by chance. The internal validity of this study should not have been threatened, since caregivers of cases and controls were likely to have similarly prepared for the home visit. Our sample size of 702 is insufficient to examine specific exposureoutcome relationships. For example, among the 80 cases with burns, smoke detectors could have played a potential mitigating role only for the 2 cases in which the burns were the result of a fire in the home. Although we excluded hospital admissions a priori because of lack of power, Kendrick and colleagues found substantially stronger associations between hazards and hospital admissions for injuries than for emergency department visits, which suggests a need for studies large enough to capture sufficient admissions to hospital. ${ }^{17}$ Because we analyzed the ig hazards separately, readers are cautioned that the probability of having more than one statistically significant association is greater than the nominal $5 \%$ level. We eschewed methods to adjust for multiple comparisons (e.g., the Bonferroni correction) since they assume statistical independence among the comparisons and tend to be too conservative. ${ }^{18}$

The homes of injured and noninjured children included in our study differed with respect to several hazards for falls, burns, poisonings and ingestions. These differences are too small to be incorporated into screening strategies aimed at identifying families at increased risk for home injuries. However, physicians should counsel for specific hazards supported by evidence of their effectiveness. ${ }^{6}$ They should also advocate for the control of hazards that markedly increase the risk of serious injury, such as baby walkers. In addition, clinicians should consider that the presence of any hazard may indicate an increased risk for home injuries beyond those directly related to that specific hazard. Therefore, families with any home hazard may be candidates for interventions for other types of home hazards. Unfortunately, conflicting evidence prevents the clear endorsement 
Box 1: Tips for physicians to help counsel patients on home safety

\section{Physician counselling}

- Physician counselling is evidence-based, but only for some safety measures

- Patients listen to physician advice about motor vehicle restraint systems, smoke detectors, safe storage of cleaning agents and hot water temperature

- Physicians should counsel patients about high-risk home hazards such as baby walkers despite absence of evidence for effectiveness of counselling

Home injury prevention checklists

- Rourke Baby Record: www.cfpc.ca/English/cfpc /programs/patient care/rourke baby

- Injury Prevention Program (TIPP): www.aap.org/family/tippmain.htm

of specific counselling interventions as found in, for example, the Rourke baby record ${ }^{19}$ or generalized interventions such as home visits focused on several hazards simultaneously (Box I). Future research should focus on understanding factors that motivate caregivers to enact some safety practices and ignore others.

This article has been peer reviewed.

From the IWK Health Centre and the Department of Pediatrics, Dalhousie University, Halifax, NS (LeBlanc); the Department of Pediatrics, McGill University, Montréal, Que. (Pless); the Children's Hospital of Eastern Ontario and the Department of Pediatrics, University of Ottawa, Ottawa, Ont. (King); the Department of Psychology, IWK Health Centre, and the Department of Pediatrics, Dalhousie University, Halifax, NS (Bawden); the Hôpital SainteJustine and the Department of Pediatrics, Université de Montréal, Montréal, Que. (Bernard-Bonnin); the Department of Pediatrics, University of Alberta, Edmonton, Alta. (Klassen); and the Department of Pediatrics and Child Health, University of Manitoba, Winnipeg, Man. (Tenenbein)

Competing interests: None declared.

Contributors: All of the authors contributed to the design of the study, and all except for Harry Bawden participated in the data collection. John LeBlanc was the principal author, and the coauthors provided substantial input to the drafts. All of the authors approved the final version.
Acknowledgements: This study could not have been executed without the tireless efforts of its project manager, Barbara Willard. Dr. Yvonne Robitaille was instrumental in constructing a methodologically sound design. Dr. Anthony Almudevar assisted with the analysis.

This work was supported by funding from the National Health Research and Development Program (grant no. 6605-4290-BF).

\section{REFERENCES}

I. Baker S, O'Neill B, Ginsburg M, et al. The injury fact book. 2nd ed. New York: Oxford University Press; 1992

2. Choinière R, Robitaille Y. Methodological considerations and overall profile of mortality, hospitalizations and emergency room visits. In: Beaulne G, editor. For the safety of Canadian children and youth. Ottawa: Public Health Agency of Canada; I997. p. II-47.

3. DiGuiseppi C, Higgins JP. Systematic review of controlled trials of interventions to promote smoke alarms. Arch Dis Child 2000;82:34I-8.

4. Kendrick D, Marsh P, Fielding K, et al. Preventing injuries in children: cluster randomised controlled trial in primary care. $B M J$ I999;318:980-3.

5. Kelly B, Sein C, McCarthy PL. Safety education in a pediatric primary care setting. Pediatrics I987;79:818-24.

6. DiGuiseppi C, Roberts IG. Individual-level injury prevention strategies in the clinical setting. Future Child 2000;10:53-82.

7. Rodgers GB. The safety effects of child-resistant packaging for oral prescription drugs. Two decades of experience. JAMA I996;275:166I-5.

8. McLoughlin E, MacGuire A. The causes, cost and prevention of childhood burn injuries. Am J Dis Child 1990;144:677-83.

9. DiGuiseppi C, Roberts I, Li L. Smoke alarm ownership and house fire death rates in children. J Epidemiol Community Health 1998;52:760-I.

Io. Marshall SW, Runyan CW, Bangdiwala SI, et al. Fatal residential fires: Who dies and who survives? JAMA I998;279:1633-7.

II. Runyan CW, Bangdiwala SI, Linzer MA, et al. Risk factors for fatal residential fires. N Engl J Med I992;327:859-63.

I2. Schlesselman JJ. Case-control studies: design, conduct, analysis. New York: Oxford University Press; 1982

13. Board of Review - Baby Walkers. Board of review inquiring into the nature and characteristics of baby walkers. Available: www.babywalkers-marchettes.ca (accessed 2006 Jul 26).

I4. Dershewitz RA, Williamson JW. Prevention of childhood household injuries: controlled clinical trial. Am J Public Health 1977 ; 67:1148-53.

I5. Clamp M, Kendrick D. A randomised controlled trial of general practitioner safety advice for families with children under 5 years. $B M J$ I998;316:1576-9.

I6. Glik D, Greaves P, Kronenfeld J, et al. Safety hazards in households with young children. J Pediatr Psychol I993;I8:115-31.

I7. Kendrick D, Watson M, Mulvaney C, et al. How useful are home safety behaviours for predicting childhood injury? A cohort study. Health Educ Res 2005;20:709-18.

I8. Perneger TV. What's wrong with Bonferroni adjustments. BMJ I998;316:1236-8.

I9. College of Family Physicians of Canada. Rourke Baby Record. Mississauga (ON): The College. Available: www.cfpc.ca/English/cfpc/programs/patient care/rourke baby (accessed 2006 Jul 26).

Correspondence to: Dr. John C. LeBlanc, IWK Health Centre, 5850 University Ave., PO Box 9700, Halifax NS B3K 6R8; fax 902 470-6913; john.leblanc@dal.ca

\section{LEADERSHIP}

$C M A J$ is a founding member of the International Committee of Medical Journal Editors, an organization that is devoted to ensuring the highest integrity in scientific publishing and is a driving force in the mandatory registration of clinical trials. 